\title{
Strategi Sukses K-Pop Memasuki Pasar Musik Mainstream: \\ Bighit Entertainment, BTS, dan 'Army'
}

\author{
Ni Made Santika Krisna Diari ${ }^{(1)}$ \\ Luh Putu Mahyuni ${ }^{(2)}$ \\ Universitas Gadjah Mada ${ }^{(1)}$ \\ Universitas Pendidikan Nasional (2) \\ santika.krisnadiari@gmail.com ${ }^{(1)}$ \\ mahyuniluhputu@undiknas.ac.id (2)
}

\begin{abstract}
The purpose of this study is to identify the differentiation strategy of K-pop agency in the digital economic era, as well as the role of fans in their application. The focus of this research is on BigHit Entertainment the agency that manages the current phenomenal K-pop group, namely BTS; as well as the behavior of their fans. This descriptive qualitative research uses secondary data collected from articles and videos related to the agency, the group, and their fans; as well as observational data from social media, like Twitter. This research use Miles and Huberman model of analisys techniques which include data reduction, data presentation, and conclusion drawing. The results of analysis show that BigHit Entertainment applied the strategies of product differentiation, marketing channel differentiation and image differentiation in order to obtain competitive advantage. Those differentiation strategies is in line with the tactical steps of digital marketing that begin with an understanding of consumer behavior, and then continued with human-oriented marketing for brand attractiveness, content marketing for brand recognition, omnichannel marketing for brand commitment, and engagement marketing for brand affinity. During the process of strategy implementation, fans that mostly consist of young people and women played a major role as a good brand advocate and contents distributors.
\end{abstract}

Keywords: Differentiation strategies; value chain; marketing 4.0; customer path 5A; K-pop (Korean pop); BTS; BigHit Entertainment 
Penelitian ini bertujuan untuk mengidentifikasi strategi diferensiasi agensi K-pop dalam era ekonomi digital, serta peran penggemar dalam penerapannya. Fokus penelitian ditujukan pada BigHit Entertainment, agensi yang memanajemeni grup K-pop fenomenal masa kini, yakni BTS; serta perilaku penggemarnya. Penelitian kualitatif deskriptif ini menggunakan data sekunder berupa kumpulan artikel dan video, serta data hasil observasi pada media sosial Twitter. Teknik analisis menggunakan model Miles dan Huberman yang meliputi reduksi data, penyajian data, dan penarikan kesimpulan. Hasil penelitian menunjukkan bahwa BigHit Entertainment mengimplementasikan strategi diferensiasi produk, diferensiasi saluran, dan diferensiasi citra untuk memperoleh keunggulan kompetitif. Srategi diferensiasi tersebut sejalan dengan langkah-langkah pemasaran taktis era digital yang diawali dengan pemahaman terhadap prilaku konsumen, dan kemudian dilanjutkan dengan pemasaran yang berorientasi pada manusia untuk daya tarik merek, pemasaran konten untuk pengenalan merek, pemasaran omnisaluran untuk komitmen merek, dan pemasaran pelibatan untuk afinitas merek. Dalam proses implementasi strategi tersebut, penggemar yang sebagian besar terdiri atas kaum muda dan perempuan berperan besar sebagai penganjur merek dan distributor yang baik.

Kata Kunci: Strategi diferensiasi; value chain; pemasaran 4.0; customer path 5A; K-pop (Korean pop); BTS; BigHit Entertainment 


\section{PENDAHULUAN}

Selama belasan tahun globalisasi K-pop berkembang pesat melalui fenomena Korean Wave melibatkan puluhan grup K-pop, soloist, maupun band K-pop yang menduduki tanggatangga musik mancanegara secara berkala (Messerlin \& Shin, 2013). Namun selama beberapa tahun tersebut K-pop masih belum dapat masuk ke dalam ranah musik mainstream. Para pendengarnya pun masih seputar komunitas-komunitas K-pop atau pencinta kebudayaan Korea. Hingga pada tahun 2017 lalu, salah satu grup boyband K-pop bernama BTS berhasil meraih penghargaan 'Top Social Artist Award' dalam ajang penghargaan bergengsi Amerika, Billboard Music Award mengalahkan mega bintang Justin Bieber, dan menjadi grup K-pop pertama dengan penjualan album terbesar di Korea Selatan mencapai 3.021.822 unit (Soompi: 2019).

Dalam lingkungan bisnis yang bersifat homogen persaingan menjadi begitu ketat, monopoli oleh perusahaan besar yang telah beroperasi selama puluhan tahun umum terjadi (Darma, 2006; Darma, 2012). Demikian pula dalam industri K-pop. Dimana agensi besar seperti; SM Entertaiment, JYP Entertainment, dan YG Entertainment yang dikenal dengan sebutan 'Big Three' memiliki kekuatan finansial dan pengaruh besar dalam ekosistem dunia hiburan di Korea dan mendominasi pasar K-pop. Memudahkan grup K-pop yang dimanajemeni untuk melakukan promosi di berbagai acara TV nasional, jika dibandingkan mereka yang berasal dari agensi kecil. Namun pemusatan promosi lewat media sosial dengan target penggemar internasional yang diterapkan oleh BigHit Entertainment ternyata berhasil membawa BTS mencapai kepopuleran yang sekarang (CNBC: 2017) dan mengungguli pesaing besarnya tersebut.

Sejak pertengahan tahun 1990-an, agensi hiburan telah memegang peranan yang lebih signifikan dalam perkembangan industri musik Korea Selatan dibandingkan dengan label rekaman maupun perusahaan musik (Negus: 2015). Agensi K-pop menerapkan strategi penciptaan nilai K-pop berupa rangkaian proses yang - oleh Profesor Lee Dong-yeon (SCMP: 2018) disebut dengan 'Idol Farm System'. Sebuah sistem penciptaan idol di mana agensi merekrut bakat-bakat yang menjanjikan sejak usia dini (mulai dari umur 9-11 tahun) dan melatih mereka secara intensif selama beberapa tahun - memberikan pelatihan bahasa, olah vokal, menari, dan menempatkan mereka dalam asrama (Messerlin \& Shin: 2013) - sebelum akhirnya debut menjadi idol group, soloist, maupun duo. Setiap agensi di Korea Selatan menerapkan sistem yang serupa, termasuk BigHit Entertainment. Kenyataan tersebut 
menimbulkan pertanyaan: apakah yang membedakan BigHit Entertainment dibandingkan agensi K-pop lain?

Dengan demikian, penelitian ini bertujuan untuk mengidentifikasi strategi differensiasi BigHit Entertainment ditinjau berdasarkan kontribusi yang diberikan pada setiap aktivitas rantai nilai dalam proses produksi produk K-pop. Serta strategi pemasaran dalam era digital dengan pertimbangan pemberitaan media yang menyebutkan bahwa SNS dan peran aktif penggemar di media sosial merupakan salah satu faktor kesuksesan BTS dalam memasuki pasar mainstream industri musik dunia.

\section{Strategi Diferensiasi}

Strategi diferensiasi (diferentiation strategy) merupakan salah satu dari tiga strategi generik Porter yang dapat diterapkan oleh perusahaan untuk mencapai keunggulan kompetitif, yang memungkinkan perusahaan untuk membangun loyalitas merek, mendapatkan pelanggan yang relatif tidak menunjukkan sensitivitas terhadap harga yang lebih rendah, dan meningkatkan margin keuntungan (Pranata dan Darma, 2014; Krisnamurti dan Darma, 2015; Kanten dan Darma, 2017).

Terdapat lima jenis diferensiasi (Kotler, 2002), antara lain; (1) diferensiasi produk (product differentiton) yang berkaitan dengan fisik produk, (2) diferensiasi pelayanan (service differentiation) yang berkaitan dengan pelayanan yang menyertai produk, (3) diferensiasi personil (personnel differentiation) yang berkaitan dengan sumber daya manusia, (4) diferensiasi saluran (channel differentiation) yang berkaitan dengan jalur distribusi, dan (5) diferensiasi citra (image differentiation) yang berkaitan dengan citra maupun merek perusahaan.

Selain itu, diferensiasi juga dapat diciptakan melalui fokus terhadap tiga dimensi diferensiasi (Kartajaya, 2007; Krisnamurti dan Darma, 2015), diantaranya; konten (content) yang berkaitan dengan bentuk penawaran, konteks (context) yang berkaitan dengan cara penawaran, dan infrastruktur (infrastructure) yang berkaitan dengan faktor yang memungkinkan diferensiasi terealisasi.

\section{Marketing 4.0}

Pemasaran 4.0 merupakan pemasaran yang berorientasi pada perubahan alami dari jalur pelanggan dalam ekonomi digital, yang menggabungkan interaksi online dan offline antara perusahaan dan pelanggan, memadukan gaya dengan substansi dalam membangun merek, dan akhirnya melengkapi konektivitas mesin-ke-mesin dengan sentuhan manusia-ke-manusia untuk memperkuat keterlibatan pelanggan (Kartajaya dan Setiawan, 2017; Dewi dan Darma, 
2019; Darma, 2019). Kaum muda, perempuan, dan warganet merupakan segmen konsumen yang paling berpengaruh dalam era digital. Mereka adalah trendsetter, pembicara merek, dan penghubung sosial.

Konsumen 4.0 melalui lima tahap perjalanan (customer path 5A) untuk menjadi pelanggan yang setia, yakni; tahap menyadari keberadaan merek (aware), tahap ketertarikan untuk mengenal merek (appeal), tahap pencarian informasi mengenai merek secara aktif (ask), tahap konsumsi/pembelian (act), dan tahap penganjuran merek kepada konsumen baru (advocate).

Pemasaran taktis dalam ekonomi digital diawali dengan pemahaman terhadap prilaku konsumen digital, dan kemudian dilanjutkan dengan;

(1) Pemasaran yang berorientasi pada manusia untuk daya tarik merek. Dilakukan dengan penciptaan merek yang memenuhi enam atribut manusia, yakni; fisik, intelektual, sosiabilitas, emosional, kepribadian, dan moralitas.

(2) Pemasaran konten untuk keingintahuan tentang merek, yang mencakup proses menciptakan, memilih, membagi, dan memperbesar konten yang menarik, relevan, dan berguna untuk kelompok khayalak yang jelas demi menciptakan percakapan tentang konten terkait.

(3) Pemasaran omnisaluran untuk komitmen merek. Memadukan pengalaman, media tradisional dan digital.

(4) Pemasaran pelibatan untuk afinitas merek. Peningkatan pengalaman konsumen dengan memanfaatkan aplikasi ponsel, CRM sosial, dan gamification.

\section{Value Chain}

Value chain, atau rantai nilai adalah sebuah pandangan yang melihat bisnis sebagai suatu rangkaian aktivitas tranformasi input menjadi output yang bernilai bagi pelanggan (Pearce dan Robinson, 2008). Value chain tidak hanya membahas mengenai 'pasokan' layaknya supply chain, tetapi juga mengenai 'permintaan'. Sebab sesungguhnya 'dorongan permintaan'-lah yang memicu terjadinya aktivitas dan proses value-added (Sabri dan Shaikh, 2010; Saefulloh dan Darma, 2014; Handika dkk., 2018).

Rantai nilai dibagi ke dalam dua kategori aktivitas; (1) primer (primary activity) yang terdiri atas aktivitas logistik kedalam, operasi, logistik keluar, pemasaran \& penjualan, serta pelayanan, dan (2) aktivitas pendukung (support activity) yang terdiri atas administrasi umum, manajemen sumber daya manusia, riset \& pengembangan, serta pengadaan (Porter dalam 
Pearce \& Robinson, 2008; Darma, 2018). Aktivitas primer adalah aktivitas fisik penciptaan produk, sedangkan aktivitas pendukung aalah aktivitas yang mendukung proses penciptaan secara keseluruhan melalui penyediaan infrastruktur atau input yang memungkinkan aktivitas primer berjalan secara berkesinambungan (Sedarmayanti, 2016).

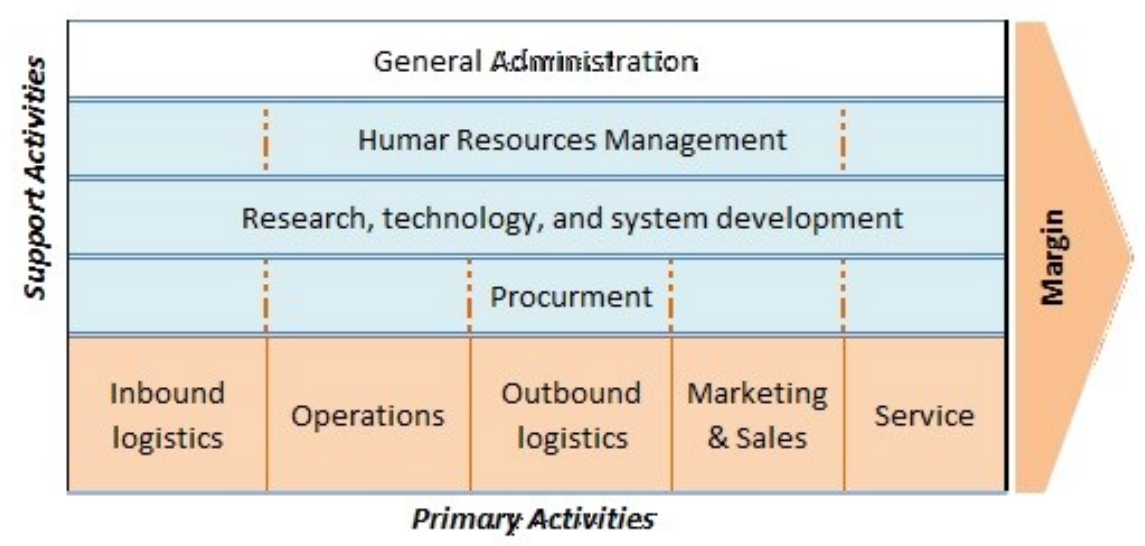

\section{Gambar 1. Model Rantai Nilai Porter}

\section{METODE PENELITIAN}

Penelitian ini bersifat kualitatif deskriptif. Penelitian dilakukan untuk mengeksplorasi dan atau memotret situasi sosial yang diteliti secara menyeluruh, luas, dan mendalam (Sugiyono, 2015). Menggunakan metode penelitian studi kasus atau case-study Cresswell (dalam Raco, 2010) yang bertujuan untuk mendalami suatu kasus tertentu secara mendalam dengan melibatkan pengumpulan beraneka informasi dari berbagai sumber. Penelitian menggunakan sumber data sekunder yang berasal dari artikel-artikel berita online, video wawancara yang diperoleh dari YouTube terkait dengan K-pop, BTS, dan BigHit Entertainment. Serta observasi interaksi di media sosial Twitter antara agensi, artis, konsumen, serta akun resmi lainnya.

Analisis data menggunakan model Miles dan Huberman (dalam Sugiyono, 2015) yang meliputi proses reduksi data, penyajian data, dan penarikan kesimpulan. Data-data berupa artikel dan video yang telah dikumpulkan, dibaca dan diamati kembali untuk direduksi melalui proses koding, dimana kutipan-kutipan dari video maupun artikel tersebut dimasukkan ke dalam kolom yang sesuai pada tabel koding yang dibuat sedemikian rupa berdasarkan aktivitas rantai nilai Porter. 


\section{PEMBAHASAN}

\section{Rantai Nilai Agensi K-pop, BigHit Entertainment}

K-pop menyajikan diferensiasi baik dari segi produk maupun servis jika dibandingkan dengan musik mainstream (western music). Pada pertengahan tahun 1980-an, saat musik disco mulai menghilang dan Michael Jackson pensiun dari dunia hiburan, agensi K-pop mengambil kesempatan dengan menyasar segmen tampilan musik yang disertai koreografi dengan intensitas tinggi (Messerlin \& Shin, 2013). Kemudian seiring perkembangan teknologi informasi, agensi hiburan Korea memanfaatkan YouTube sebagai media distribusi untuk mencapai konsumen global. Dari segi servis, K-pop meningkatkan customer experience melalui private event seperti fanmeeting dan fansign yang diselenggarakan secara khusus dalam suasana yang lebih akrab - untuk penggemar grup idol terkait, serta tentunya melalui konser. Proses produksi grup K-pop melalui sebuah sistem yang dikenal dengan 'idol farm system' dimulai dengan proses audisi, training, pembentukan grup, hingga debut. Dalam penerapan sistem ini, agensi dikenal memiliki kontrol yang kuat terhadap para artis. Kontrol agensi tidak hanya mencakup musik dan performance, tetapi juga kehidupan pribadi para artis. Proses distribusi dan pemasaran awalnya dilakukan secara tradisional melalui penampian di berbagaik acara musik dan tentunya penjualan album fisik. Kemudian seiring perkembangan teknologi, agensi mengembangkan pemasaran digital dan distribusi konten melalui media sosial serta streaming platform.

Proses produksi grup K-pop melalui sebuah sistem yang dikenal dengan 'idol farm system' dimulai dengan proses audisi, training, pembentukan grup, hingga debut. Dalam penerapan sistem ini, agensi dikenal memiliki kontrol yang kuat terhadap para artis. Kontrol agensi tidak hanya mencakup musik dan performance, tetapi juga kehidupan pribadi para artis. Proses distribusi dan pemasaran awalnya dilakukan secara tradisional melalui penampian di berbagaik acara musik dan tentunya penjualan album fisik. Kemudian seiring perkembangan teknologi, agensi mengembangkan pemasaran digital dan distribusi konten melalui media sosial serta streaming platform.

Berdasarkan model rantai nilai Porter, aktivitas rantai nilai K-pop pada umumnya terdiri dari; (1) rekrutmen/akuisisi bakat, (2) persiapan, penciptaan $\&$ pengembangan produk K-pop, (3) distribusi, (4) penjualan dan pemasaran, serta (5) CRM. Tabel 1 berikut merupakan rekapitulasi aktivitas-aktivitas yang membedakan BigHit Entertainment dengan agensi K-pop pada umumnya berdasarkan aktivitas primer dan sekundernya. Yang mana berdasarkan tabel dapat dilihat bahwa perbedaan banyak ditemukan pada empat aktivitas primer dan dua aktivitas 
pendukung. Sementara itu, pada aktivitas primer rekrutmen/akuisisi bakat, serta pada aktivitas pendukung berupa pengadaan/pembelian dan manajemen sumber daya manusia tidak ditemukan perbedaan yang signifikan.

Tabel 1

\section{Rekap Aktivitas Pembeda Pada Rantai Nilai BigHit Entertainment}

\begin{tabular}{|c|c|c|}
\hline $\begin{array}{l}\text { Aktivitas } \\
\text { Primer }\end{array}$ & Rekrutmen/akuisisi bakat & - \\
\hline & $\begin{array}{l}\text { Persiapan, penciptaan, dan } \\
\text { pengembangan produk K-pop }\end{array}$ & $\begin{array}{l}\text { a. Idol diberi kebebasan untuk ikut berkontribusi dalam proses } \\
\text { produksi musik sejak dini } \\
\text { b. Pengurangan kontrol terhadap kehidupan personal para idol } \\
\text { c. Pemusatan pelatihan insentif pada koreografi dan olah vokal } \\
\text { untuk memperoleh penampilan yang maksimal } \\
\text { d. Hibridisasi K-pop dengan laku hip-hop mengunakan formula } \\
\text { grup idol } \\
\text { e. Serialisasi konten K-pop } \\
\text { f. Ragam konten dan jenis produk K-pop } \\
\text { g. Memimalisasi lokalisasi }\end{array}$ \\
\hline & Distribusi & $\begin{array}{l}\text { a. Distribusi berbagai konten melalui media sosial secara } \\
\text { maksimal } \\
\text { b. Pengunggahan konten K-pop secara gratis di berbagai } \\
\text { streaming platform }\end{array}$ \\
\hline & Pemasaran \& Penjualan & $\begin{array}{l}\text { a. Fokus promosi melalui media sosial } \\
\text { b. Kolaborasi dalam produksi merchandise } \\
\text { c. Memperluas target pemasaran secara demografis } \\
\text { d. Penciptaan platform untuk meningkatkan customer experience } \\
\text { e. Mempertahankan antusiasme konsumen lewat content spoilers }\end{array}$ \\
\hline & $\begin{array}{l}\text { CRM (customer relationship } \\
\text { management) }\end{array}$ & $\begin{array}{l}\text { a. Mengajak serta konsumen dalam aktivitas CSR } \\
\text { b. Registrasi trademark untuk nama fandom } \\
\text { c. Komunikasi timbal-balik yang aktif antara penggemar dengan } \\
\text { agensi dan idol lewat media sosial }\end{array}$ \\
\hline $\begin{array}{l}\text { Aktivitas } \\
\text { Pendukung }\end{array}$ & Pengadaan/Pembelian & - \\
\hline & $\begin{array}{l}\text { Riset Teknologi dan } \\
\text { Pengembangan }\end{array}$ & $\begin{array}{l}\text { a. Idol ikut serta memberikan kontribusi dalam proses } \\
\text { penciptaan/pengembangan produk kolaborasi }\end{array}$ \\
\hline & $\begin{array}{l}\text { Manajemen Sumber Daya } \\
\text { Manusia }\end{array}$ & - \\
\hline & Administrasi umum & a. Idol ikut serta secara aktif dalam pengelolaan akun media sosial \\
\hline
\end{tabular}

Diferensiasi memungkinkan perusahaan untuk membangun loyalitas merek, mendapatkan pelanggan yang relatif tidak menunjukkan sensitivitas terhadap harga yang lebih rendah, dan meningkatkan margin keuntungan. Kotler (2002) menyebutkan terdapat lima jenis diferensiasi penawaran antara lain dari segi produk, pelayanan personil, saluran dan citra. Berdasarkan rekapitulasi perbedaan aktivitas-aktivitas dalam rantai nilai BigHit seperti yang telah dijabarkan pada tabel diatas, tampak bahwa diferensiasi yang ditawarkan oleh BigHit adalah berupa differensiasi produk, saluran, dan citra. 


\section{Strategi Diferensiasi BigHit Entertainment}

(1) Differensiasi produk

BigHit menawarkan diferensiasi produk lewat proses penciptaannya. Produk K-pop terdiri dari servis dan barang berupa album/lagu yang dibawakan oleh grup K-pop. Berbeda dengan agensi pada umumnya yang memberikan pelatihan multi entertainment kepada calon artis, BigHit tampak memfokuskan pelatihan pada sisi musikalitas serta performance. Selain itu BigHit memberikan kebebasan pada para artis untuk memilih/mendiskusikan aktivitas yang ingin dilakukan. Pengurangan kontrol terhadap kehidupan personal dan pemberian kebebasan berkreasi, menyesuaikan dengan pengalaman dan pandangan hidup para artis, menghasilkan diversifikasi topik lagu yang membuat lebih banyak orang, dari berbagai kalangan dapat berempati. BigHit mengembalikan kesan 'Korea' yang memudar akibat globalisasi/lokalisasi konten K-pop dengan memadukan unsur tradisional dalam musik maupun penampilan di atas panggung.

(2) Differensiasi saluran

Kelemahan dari segi finansial dan pengaruh dalam industri musik Korea di awal karir BigHit Entertainment, mengaharuskan agensi ini mencari cara untuk mempromosikan grup K-pop ciptaannya dengan biaya yang minimum. Media sosial yang notabene rendah biaya namun dapat mencapai area distribusi yang luas menjadi pilihan. Dalam era digitalisasi hal ini tentunya menjadi langkah yang menguntungkan. Melalui distribusi secara maksimal melalui berbagai platform, meningkatkan komunikasi aktif dengan para penggemar di seluruh dunia dengan konten yang lebih 'genuine' menceritakan tentang kehidupan sehari-hari para artis, membawa kepopuleran yang menjadi dasar kuat yang memudahkan pendistribusian konten/produk K-pop lainnya di masa kini maupun mendatang.

(3) Differensiasi citra

Kontrol kuat agensi K-pop pada umumnya terhadap para artis, dengan membatasi pengekspresian pribadi serta pemberian konsep terhadap karakter masing-masing anggota untuk memenuhi harapan para penggemar, secara signifikan justru memudarkan citra 'manusiawi' pada mereka. Kebebasan yang diberikan oleh BigHit Entertainment tidak hanya membawa diferensiasi dari segi produk, namun juga citra perusahaan. BigHit menanamkan enam atribut merek yang berorientasikan pada manusia, yakni; fisik, intelektualitas, sosiabilitas, emosional, kepribadian, dan moralitas sejak dini. Hal ini dilakukan dengan pembebasan untuk berkontribusi bagi para artis dalam produksi musik, peningkatan aktivitas 
berbagi konten lewat media sosial secara langsung oleh para artis, dan aktivitas filantropi yang sejalan dengan tema musik yang ditawarkan.

\section{Penerapan Pemasaran 4.0 oleh BigHit Entertainment}

\section{Mengenal dan Memahami Prilaku Konsumen Digital}

Bang Si-hyuk (BSH) sebagai CEO dari BigHit entertainment menyadari perubahan zaman ke arah hiperkoneksi, di mana dunia terhubung secara real-time dan keberadaan kaum muda (umur 10-20 tahunan) sebagai digital natives. BSH memperhatikan perkembangan budaya penggemar K-pop di dunia digital, dimana para warnaget yang notabene merupakan kaum muda berbagai dan menikmati konten digital. Contohnya video reaksi MV K-pop yang diunggah di YouTube. Oleh karena itu, BSH membentuk sebuah grup idol yang merepresentasikan kaum muda dan menceritakan permasalahan yang dialami oleh kaum muda melalui musik yang mereka bawakan.

\section{Membangun Merek Berorientasi Manusia}

Seperti yang telah dijelaskan pada bagian diferensiasi merek. BigHit Entertainment membangun merek berlandaskan enam atribut manusia. BigHit, melalui musik BTS menarik pelanggan baik secara fisik, intelektual, sosial, emosional, kepribadian, dan moralitas. Musik yang auntentik menceritakan berbagai permasalahan sosial serta dilema hidup, secara efektif menarik empati pendengar yang memiliki masalah serupa. Kemudian melalui pesan positif yang ditambahkan didalamnya, secara efektif meredakan kegelisahan para pendengar dan memberikan mereka harapan. Hal ini sejalan dengan motto BigHit Entertainment, yakni menyajikan 'musik dan artis untuk penyembuhan'.

\section{Pemasaran Konten}

Kepopuleran dan kesuksesan BTS, diakui oleh pendiri BigHit sendiri sebagai hal yang tidak terduga. Kelemahan finansial yang kemungkinan menjadi salah satu faktor dalam memaksimalkan jalur distribusi digital, menunjukkan bahwa pemasaran konten telah dilakukan oleh BigHit Entertaiment pada awal karirnya bertujuan untuk membangun merek. Meningkatkan kesadaran penggemar K-pop akan merek BTS melalui konten video yang diunggah ke kanal YouTube dan cuitan Twitter dari anggota BTS. Target pelanggan yang dituju pada saat itu tentunya komunitas penggemar K-pop. Tema konten mencakup keseharian BTS yang diproduksi secara internal oleh agensi beserta anggota BTS. Penguatan konten dilakukan melalui kerjasama dengan berbagai lini bisnis dan merek ternama yang memiliki pengaruh pada suatu kelompok tertentu. Misalnya Hyundai Motor, UNICEF, dan Lotte Duty 
Free. Hal ini tentunya memungkinkan berkat citra positif yang telah dibangun terlebih dahulu oleh merek BTS.

4. Pemasaran Omnisaluran \& Peningkatan Pengalaman Pelanggan

Pemasaran yang memadukan saluran online dan offline, serta peningkatan pengalaman pelanggan tampak baru gencar dilakukan oleh BigHit setelah kepopuleran BTS memasuki ranah musik mainstream dan jumlah penggemar BTS di media sosial meningkat hingga Adapun beberapa penerapan pemasaran omnisaluran yang telah dilakukan oleh BigHit, yaitu; 'ARMYPEDIA', serta siaran langsung konser BTS di stadium Wembley dan fanmeeting bertajuk '5th Muster - Magic Shop' di Seoul melalui aplikasi V-live.

Melalui 'ARMYPEDIA', BigHit meningkatkan interaksi dan pengalaman penggemar secara online maupun offline dengan mengajak mereka untuk menemukan potongan puzzle berupa QR code yang telah disebarkan sebelumnya. Penanyangan siaran langsung konser dan fanmeeting melalui aplikasi siaran khusus artis V-live memberikan kesempatan bagi penggemar yang kurang beruntung dalam mendapatkan tiket untuk tetap ikut dalam euforia acara terkait. Namun tentunya konten ini temasuk dalam konten premium yang berbayar.

\section{Peran Penggemar Dalam Strategi Diferensiasi dan Pemasaran 4.0}

Dalam marketing 4.0, pelanggan/konsumen memiliki peranan signifikan dalam menciptakan kesadaraan terhadap keberadaan suatu brand, baik yang bersifat positif maupun negatif. Tingkat loyalitas pelanggan digambarkan dalam lima tahap perjalanan/jalur pelanggan yakni; aware, appeal, ask, act, dan advocate. Terkait dengan hal tersebut dan berdasarkan data yang dikumpulkan, sebagain besar penggemar BTS - yang dikenal dengan sebutan 'ARMY' telah mencapai jalur pelanggan kelima, yakni jalur advocate. Mereka merupakan media distribusi aktif yang merekomendasikan merek BTS secara terintergrasi secara online kepada pengikut mereka, dan secara offline kepada teman, rekan kerja, maupun sanak saudara. Berdasarkan tiga tingkatan loyalitas yang terdapat dalam fase ini, berikut adalah rincian prilaku 'ARMY'. 
1) Rentention: pelanggan tetap memakai brand tertentu.

Sebelumnya perlu ditekankan bahwa dalam budaya penggemar K-pop terdapat berbagai macam jenis penggemar yang dibedakan secara demografis, senioritas dalam menjadi penggemar K-pop, siapa yang digemari (satu grup, banyak grup, atau anggota dalam satu grup K-pop). Terkait dengan hal ini, sebagian besar 'ARMY' masuk ke dalam kategori penggemar yang hanya menggemari satu grup. Mereka lebih mengutamakan konsumsi untuk produk dari satu grup K-pop (brand) saja, yakni BTS.

2) Repurchase: pelanggan melakukan pembelian kembali.

Kepercayaan yang telah terbentuk terhadap 'brand BTS', membuat penggemarnya sering melakukan pembelian kembali tanpa harus memperhitungkan kembali kualitas musik yang disajikan dan presentasi penjualannya. Terbukti dari tingkat penjualan pre-order album yang begitu tinggi meski belum video musik belum dirilis, serta belum ada tracklist maupun preview lagu yang akan dirilis, serta kejelasan mengenai isi paket album yang ditawarkan.

3) Advocacy: pelanggan rela mempertaruhkan reputasi pribadinya untuk merekomendasikan brand baik secara spontan ataupun tidak spontan.

Seperti yang telah dipaparkan pada bab sebelumnya. 'ARMY' memiliki prilaku yang lebih terintergrasi jika dibandingkan dengan kelompok penggemar K-pop lainnya. Mereka melakukan advocacy secara sistematis melalui permintaan pemutaran lagu di radio-radio lokal, tagar disetiap cuitan, dan membagikan informasi secara lengkap dengan tautan ke berbagai situs relevan terkait BTS kepada pelanggan baru yang tertarik dengan grup Kpop tersebut.

\section{PENUTUP}

Aktivitas-aktivitas yang membentuk rantai nilai agensi K-pop terdiri atas aktivitas rekrutmen/akuisisi bakat; persiapan, penciptaan, \& pengembangan produk K-pop (produksi Kpop); distribusi; penjualan \& pemasaran; dan CRM. Kemudian dari kelima aktivitas tersebut, BigHit Enterteinment melakukan kontribusi yang berbeda pada aktivitas produksi, distribusi, pemasaran dan manajemen konsumen. Berdasarkan perbedaan aktivitas rantai nilai tersebut kemudian dapat disimpulkan bahwa strategi diferensiasi yang diterapkan oleh BigHit adalah;

a. Strategi diferensiasi produk dengan memodifikasi 'idol trainee system', mengurangi kontrol dan memberikan kebebasar berkontribusi dalam produksi musik maupun konten K-pop. 
b. Strategi diferensiasi saluran dengan memaksimalkan distribusi melalui media sosial, terutama Twitter dan YouTube. Pengunggahan konten yang memberikan kesan genuine dan dilakukan secara konsisten.

c. Strategi diferensiasi citra dengan membentk citra merek yang positif sejak dini melalui penerapan enam atribut merek yang berorientasi pada manusia, yakni; fisik, intelektualitas, sosiabilitas, emosional, kepribadian, dan moralitas.

BigHit Entertainment memberikan contoh sukses dalam implementasi strategi pemasaran era digital (pemasaran 4.0). Yang mana sesuai dengan gagasan Kartajaya mengenai strategi taktis pemasaran era digital, BigHit mengimplementasikan langkah-langkah, sebagai berikut;

a. Memahami prilaku konsumen digital, dalam hal ini penggemar K-pop, melalui observasi terhadap budaya penggemar K-pop di dunia digital.

b. Menciptakan sebuah merek - dalam hal ini BTS - yang lebih 'manusiawi' jika dibandingkan dengan agensi K-pop lainnya. BigHit memenuhi keenam atribut (fisik, intelektual, sosiabilitas, emosional, kepribadian, dan moralitas) yang diperlukan sebuah merek untuk dapat menarik perhatian penggemar.

c. Melakukan pemasaran konten melalui media sosial seperti Twitter dan YouTube sejak sebelum grup K-pop binaan debut secara resmi.

d. Memadukan saluran online dan offline untuk meningkatkan pengalaman pelanggan/penggemar.

Keberadaan konsumen, khususnya segmen konsumen kaum muda, perempuan dan warganet memiliki peranan penting dalam mempengaruhi kultur umum pasar digital. Mereka berperan aktif dalam menjadi trendsetter dan merupakan pembicara merek serta penghubung sosial yang baik. Mereka juga merupakan pembela yang ekspresif. Dengan demikian mereka pun berperan sebagai penganjur merek dan distributor yang baik bagi perusahaan. Penggemar adalah konsumen utama dalam pemasaran K-pop. Terkait dengan hal tersebut, 'ARMY' yang merupakan sebutan bagi penggemar BTS memiliki integrasi yang lebih baik dibandingkan dengan penggemar grup K-pop lainnya dalam mendistribusikan konten BTS. Selain itu, jumlah mereka di media sosial yang mencapai puluhan juta dan tersebar di seluruh dunia menjadikan penyebaran konten ke dalam berbagai bahasa mencapi lebih cepat. 
Hasil penelitian ini mendukung teori-teori yang digunakan, yakni strategi diferensiasi dan strategi pemasaran 4.0. Yang mana melalui diferensiasi sebuah perusahaan dapat meraih keunggulan kompetitif dan penerapan strategi pemasaran perlu disesuaikan dengan perkembangan zaman untuk dapat bertahan maupun unggul dalam menghadapi persaingan. Penelitan berkontribusi dalam pemahaman secara praktis cara pengaplikasian analisis rantai nilai untuk mengidentifikasi keunggulan bersaing yang dimiliki suatu perusahaan melalui aktivitas-aktivitas yang memberikan perbedaan nilai pada hasil produksi.

Penelitian mengenai sustainabilitas grup K-pop perlu dilakukan. Penelitian dapat mempertimbangkan berbagai faktor yang dapat menghalangi keberlanjutan sebuah grup K-pop seperti misalnya skandal yang melibatkan anggota grup maupun wajib militer. Kemudian bagaimana pengaruhnya terhadap sustainabilitas bisnis perusahaan/agensi terkait. Sehubungan dengan BigHit Entertaiment, penelitian lanjutan mengenai strategi pemasaran perlu dilakukan dengan fokus pada grup baru dan kemudian dibandingkan dengan pemasaran BTS. Manajemen bisnis BigHit Entertainment setelah IPO juga dapat dijadikan pertimbangan. 


\section{DAFTAR PUSTAKA}

Caulfield, K. (2018). BTS Earns First No. 1 Album on Billboard 200 Chart With 'Love Yourself: Tear'. (Artikel elektronik Billboard). Diambil dari https://www.billboard.com/articles/columns/chart-beat/8458036/bts-earns-first-no-1album-billboard-200-chart-love-yourself-tear.

D. Kim. (2019). BTS Doubles Previous Record With Stock Pre-Orders For "Map of the Soul: Persona”. (Artikel elektronik Soompi). Diambil dari https://www.soompi.com/article/1316828wpp/bts-doubles-previous-record-withstock-pre-orders-for-map-of-the-soul-persona.

Darma, G.S. (2018). Seuntai Pesan, Menjawab Zaman. Indonesia: Pustaka Larasan Press.

Darma, G.S. (2019). Kacamata Media, Kesuksesan Bersyarat. Indonesia: Pustaka Larasan Press.

Darma, G.S., Apollo, A., Rusmanda, G., and Umar, Y. (2019). Digital Education 4.0. Indonesia: Cakra Media Utama Press.

Dewi, M.V.K., and Darma, G.S. (2019). The Role of Marketing \& Competitive Intelligence In Industrial Revolution 4.0, Jurnal Manajemen \& Bisnis, 16 (1): 1-12.

Dewi, M.V.K., and Darma, G.S. (2019). The Role of Marketing \& Competitive Intelligence In Industrial Revolution 4.0, Jurnal Manajemen \& Bisnis, 16 (1): 1-12.

Firmansyah, M.A. (2018). Prilaku Konsumen Sikap dan Pemasaran. Deepublish.

Handika, M.R., Maradona, A.F., and Darma, G.S. (2018). Strategi Pemasaran Bisnis Kuliner Menggunakan Influencer Melalui Media Sosial, Jurnal Manajemen \& Bisnis, 15 (2): 188-199.

Herman, T. (2018). BTS's Label, Big Hit Entertainment, Saw huge Gains In 2017. (Artikel elektronik Forbes). Diambil dari https://www.forbes.com/sites/ tamarherman/2018/03/22/bts-label-big-hit-entertainment-more-than-doubled-itsrevenue-in-2017/\#44b51efb3d31.

Hoffman, N.P. (2000). An Examination of the "Sustainable Competitive Advantage" Concept: Past, Present, and Future, Academy of Marketing Science Review, 2000 (4).

Kanten, I.K., and Darma, G.S. (2017). Consumer Behaviour, Marketing Strategy, Customer Satisfaction, and Business Performance, Jurnal Manajemen \& Bisnis, 14 (2): 143-165. Kartajaya, H., \& Setiawan, I. (2017). Marketing 4.0: Bergerak Dari Tradisional Ke Digital. Jakarta: PT Gramedia Pustaka Utama.

Kartajaya, H. (2007). Hermawan Kertajaya On Differentiation - Seri 9 Elemen Marketing. PT. Mizan Pustaka. 
Krisnamurti, M.B., and Darma, G.S. (2015). Strategi Diferensiasi Produk dan Jasa di Industri Digital Printing, Jurnal Manajemen \& Bisnis, 12 (1): 122-139.

Kong, H.Y. (2016). The Globaliszation of K-pop: The Interplay of External and Internal Forces. (Jurnal elektronik). Diunduh dari https://opus.hsfurtwangen.de/frontdoor/index/index/docId/1294.

Kotler, P. (2002). Manajemen Pemasaran, Jilid 1, Edisi Milenium. Jakarta: Prehallindo.

Lie, J. (2012). What is the K in K-pop? South Korean Popular Music, the Culture Industry, and National Identity. (Jurnal elektronik). Diunduh dari https://www.tobiashubinette.se/hallyu_1.pdf.

Messerlin, P.A., \& Shin, W. (2013). The K-pop Wave: An Economic Analysis. (Jurnal elektronik). Diunduh dari https://papers.ssrn.com/sol3/papers.cfm?abstract_id=2294712.

Ming, C. (2017). How K-pop Made a Breakthrough in The US in 2017. (Artikel elektronik CNBC). Diambil dari https://www.cnbc.com/2017/12/29/bts-and-big-hitentertainment-how-k-pop-broke-through-in-the-us.html.

Negus, K. (2015). The South Korean Music Industry: A Literature Review. CREATe Working Paper Series. (Jurnal elektronik). Diunduh dari https://www.create.ac.uk/publications/the-south-korean-music-industry-a-literaturereview/.

Oh, I., \& Lee, Hyo-Jung. (2014). K-pop in Korea: How the Pop Music Industry Is Changing a Post-Development Society. (Jurnal elektronik). Diunduh dari https://muse.jhu.edu/article/548545/figure/fig02.

Oh, I., \& Park, Gil-sung. (2012). From B2C to B2B: Selling Korean Pop Music in the Age of New Social Media. (Jurnal elektronik). Diunduh dari http://www.tobiashubinette.se/hallyu_2.pdf.

Oh, I. (2013). The Globalization of K-pop: Korea's Place in the Global Music Industry. (Jurnal elektonik). Diunduh dari https://www.academia.edu/4732546/The_Globalization_of_Kpop_Koreas_Place_in_the_Global_Music_Industry.

Parc, J., Messerlin, P., \& Moon, Hwy-Chang. (2016). The Secret to the Success of K-pop: The Benefits of Well-Balanced Copyrights. (Jurnal elektronik). Diunduh dari https://ecipe.org/publications/secret-success-k-pop-benefits-well-balancedcopyrights/. 
Park, Gil-sung. (2013). Manufacturing Creativity: Production, Performance, and Dissemination of K-pop, Korea Journal, 53 (4): 14-33.

Pearce II, J.A., \& Robinson, Jr., Richard B. (2008). Manajemen Strategis: Formulasi, Implementasi, dan Pengendalian. Edisi 10. Diterjemahkan oleh: Yanivi Bachtiar \& Christine. Jakarta: Salemba Empat.

Pranata, I.M.A., and Darma, G.S. (2014). Strategi Penerapan E-Commerce Dalam Meningkatkan Keunggulan Bersaing, Jurnal Manajemen \& Bisnis, 11 (1): 69-81.

Raco, J.R. (2010). Metode Penelitian Kualitatif - Jenis, Karakteristik, dan Keunggulannya. Jakarta: PT Grasindo.

Romano, A. (2018). BTS, the band that changed K-pop, explainded: The key to BTS's success: emotional resonance, sincerity, and an ARMY of fans. (Artikel elektronik Vox.). Diambil dari https://www.vox.com/culture/2018/6/13/17426350/bts-history-membersexplained.

Sabri, E.H., \& Shaikh, S.N. (2010). Lean and Agile Value Chain Management: A Guide to The Next Level of Improvement. J. Ross Publishing.

Saefulloh, D.A., and Darma, G.S. (2014). Strategi Marketing Wisata Wedding Sebagai Destinasi Alternatif, Jurnal Manajemen \& Bisnis, 11 (1): 17-34.

Sin, B. (2018). Inside the K-pop Hit Machine: How South Korea's Music Industry Has Gone Global. (Artikel elektronik SCMP). Diambil dari https://www.scmp.com/culture/music/article/2139864/inside-k-pop-hit-machine-howsouth-koreas-music-industry-has-gone.

Sugiyono. (2017). Metode Penelitian Kualitatif. Cetakan Ke-3. Bandung: Alfabeta.

Sung-mi, A. (2018). BTS' label Big Hit likely to break through W2tr market cap. (Artikel elektronik The Investor). Diambil dari http://www.theinvestor.co.kr/view.php?ud=20180529000682.

Youngdae, K. (2019). BTS The Review: A comprehensive Look at the Music of BTS. Edisi Pertama. Diterjemahkan oleh: H.J. Chung. Korea. RH Korea Co., Ltd. 